FACULDADE DE MEDICINA DA UNIVERSIDADE DE SÃO PAULO PRIMEIRA CADEIRA DE CLINICA CIRÚRGÍCA - Prof. ALfPIO CORRETA NETO*

\title{
CONSIDERAÇÕES SÔBRE UM CASO DE CÂNCER DO PILORO (*)
}

\author{
Ddo. ROLDÃO CONSONI \\ Interno do Serviço e do H. C. da Santa Casa
}

O interêsse do presente cáso reside principalmente nas dificuldades que envolveram o seu diagnóstico exato, bem como na pouca frequência da localização do câncer ao nível do piloro.

Oscilou o diagnóstico entre câncer do estômago, úlcera do bulbo duodenal, acalásia do piloro e câncer duodenal, para firmar-se, de modo praticamente seguro, em câncer/primitivo do piloro.

Passemos, sem mais demora, ao caso clínico:

Em Fevereiro de 1940, deu entrada no Serviço Cirúrgico do Prof. Alípio Correia Neto, o paciente B. O. C, de 37 anos, branco, brasileiro, casado, pedreiro.

Queixava-se de pêso, plenitude e dores na região epigástrica, de prisão de ventre e emagrecimento.

Em sua história, relata que fazia apenas 4 meses que estava doente: a moléstia começara com sensação de pêso no epigástrio após as refeições, e falta de apetite. As dores eram pouco frequentes, em pontada, e apareciam e desapareciam espontaneamente; às vezes, irradiavam-se para as faces laterais do tórax. Êste desconforto perdurava cêrca de uma hora, era geralmente condicionado pela ingestão de alimentos, e' tanto mais intenso e demorado quanto menos digerível fosse o alimento. A carne fazia-lhe muito mal; e -quanto à agua, às vezes passava até sêde porque a ingestão da mesma the aumentava grandemente a sensação de pêso e plenitude gástrica. Esta sensação de pêso e plenitude, que por vezes surgia mesmo à noite, era o que mais o incomodava; às vezes passava o dia todo com êsse mal estar.

Ao mesmo tempo, instalou-se constipação, passando regularmente 4 dias sem evacuar; nada de anormal havia nas fezes. Depois

\footnotetext{
(*) Trabalho apresentado em 4:10-940, na Secção de Clínica Cirúrgica do Primeiro. Congresso dos Estudantes de Medicina de São Paulo.
} 
de dois meses de doença, começou a ter azia e vômitos; eram vômitos tardios, em quantidade muito superior à dos alimentos ingeridos, de gôsto azedo, com mau cheiro, frequentemente com resíduos de alimentos que ingerira um a dois dias antes.

Durante êsses quatro meses de doença, emagreceu sete quilos, emagrecimento que foi muito mais pronunciado nos últimos meses.

Interrogatório geral e antecedentes - Nada de interêsse.

O exame físico nos mostra um indivíduo de aspecto abatido, pele sêca, desidratada, com musculatura atrofiada e panículo adiposo quasi desaparecido. Dientes mal conservados. Piorréia alveolar. O abdômen apresenta-se excavado; notam-se ondas peristálticas no epigástrio, que se dirigem da esquerda para a direita e de cima para baixo; tal peristaltismo foi provocado pela ingestão de agua. A palpação revela um degrau gargarejante, pouco doloroso, ao nivel da cicatriz umbilical. Não se palpa tumoraçã̃o.

Quanto ao mais, nada de particular.

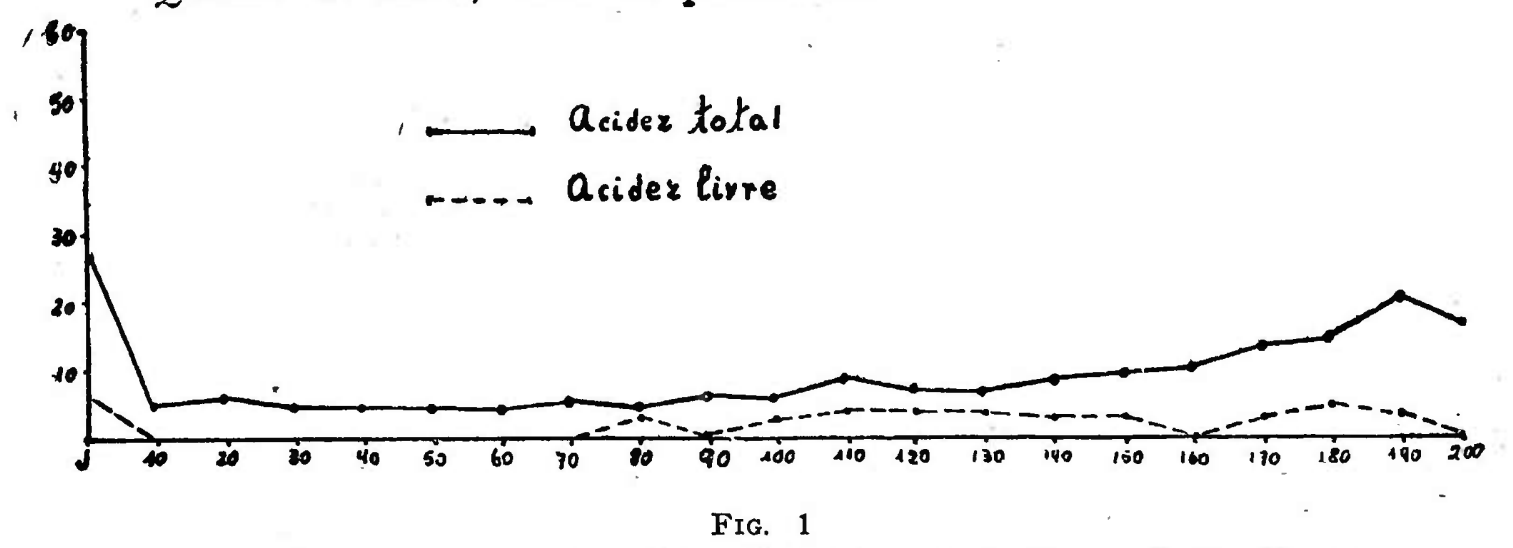

Curva obtida no examé do quimismo gástrico pela prova de Karsch-KaLK.

A história e o exame físico, como se vê, falavam em favor de câncer gástrico: assim é que havia ausência de períodos de ácalmia, as dores eram de aparecimento irregular e de pequena importância por isso que o que mais o incomodavam eram sensações contínuas de pêso e plenitude gástrica, havia aversão pela carne, a duração dos males datava de apenas quatro meses, o emagrecimento fora grande e rápido, e a idade do paciente era idade de câncer. Os vômitos de estase, bem como a desidratação da pele, indicavam grande retardo do esvaziamento gástrico. Por tudo isto, foi estabelecido o diagnóstico, naturalmente ainda sob reservas, de câncer do estômago (câncer do estômago na porção antral, que é a localização mais frequente: $80 \%$ dos casos).

Vejamos agora os elementos fornecidos pelos exames de laboratório e subsidiários:

Tempo de sangria: 1'.

Tempo de coagulação: 8'.

Exame de urina (tipo I): nada de anormal. 
Exame de fezes: nada de anormal.

Reação de Wassermann (sangue): negativa.

Contagem global: vermelhos $=4.120 .000$

$$
\text { brancos }=6.800
$$

Contagem específica: nada de particular.

Valor globular: 0,9

Taxa de hemoglobina: $92 \%$

Reservà alcalina: 69,1\%

Quimismo gástrico: A prova de KATSCH-KALK (fig. 1) revela acentuada hipo-acidez; ha, praticamente, ausência de ácido clorídrico livre. Foram retirados vinte tubos, e até o vigesimo ainda havia coloração azul do líquido de prova. O líquido de estase' media 150 c. c.

No sendimento, nada de anormal; não havia ácido lático, nem sangue oculto.

Exame radiológico (fig. 2) : "Estômago extraordinariamente aumentado de volume, dilatado, com muito líquido em jejum, e alimentos. Atonia. Estenose pilórica, provavelmente por úlcera do bulbo duodenal. Estômago altamente descompensado; peristaltismo quasi nulo"

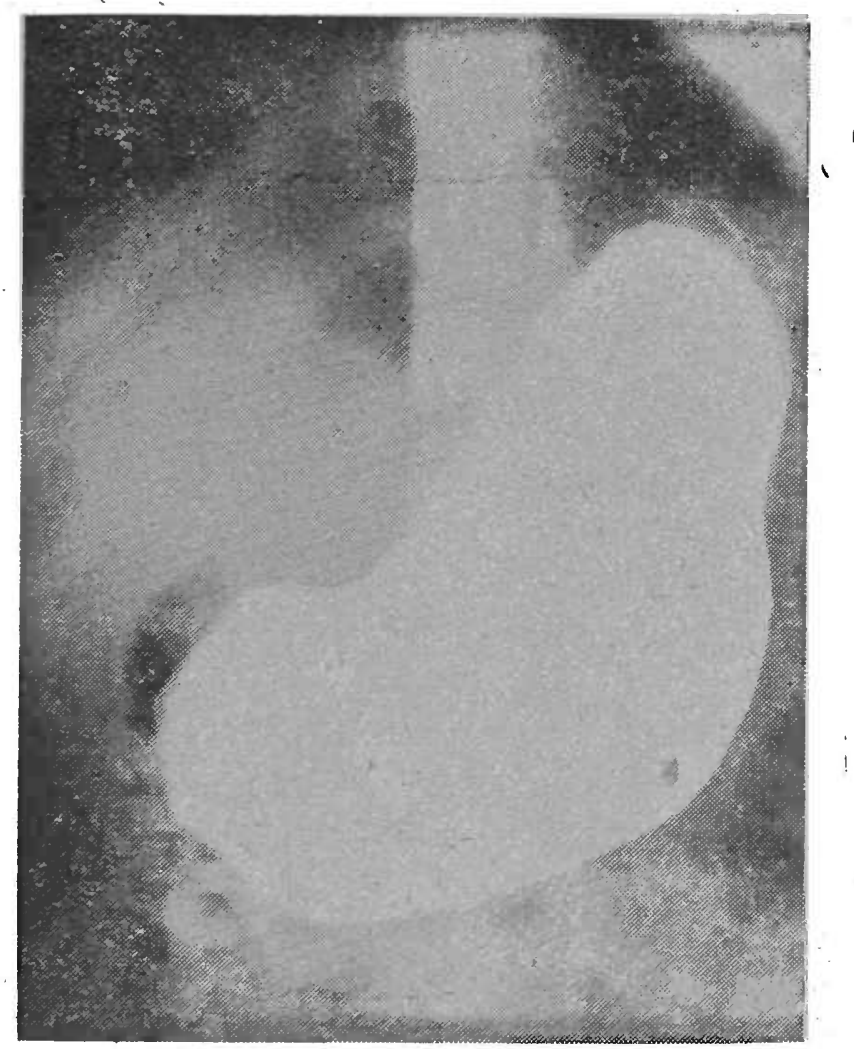

FIG. 2

Radiografia mostrando tratar-se de provável úlcera do bulbo duodenal.

Verificou-se então que a prova de $\mathrm{K}_{\mathrm{ATSCH}}-\mathrm{K}_{\mathrm{ALK}}$ indicava um grande retardo no esvaziamento do estômago, sem, naturalmente, localizar o ponto da estenose, mas fazendo entrever de modo muito nítido, ao evidenciar a acloridria, a probabilidade da natureza cancerosa do processo.

O exame radiológico mostrou que a estenose era ao nível do piloro, e, mais ainda, que era consequente a uma provável úlcera do bulbo duodenal. 
E' de se notar que os exames radioscópico e radiográfico não acusarám nicho, tendo o radiologista levantado o diagnóstico de probabilidade de úlcera duodenal muito logicamente, pois năo havia defeitos no estômago, e ainda porque cêrca de $90 \%$ das lesões obstrutivas correm por conta de lesão duodenal.

Havia assim certo conflito entre a história clinica, depondo fortemente em favor de câncer gástrico; e o exame radiológiço falando em favor de úlcera do bulbo duodenal. A prova de Katsch-KalK falava também em favor de câncer, mas não excluia dé modo ábsoluto a presença de uma úlcera. Em um ponto, porém, todos os exames estavam concordes: é que havia uma intensa estenose.

Diante do quadro clinico referido, e como não tivesse sido possível evidenciar de modo definitívo qualquer lesão orgânìca no estômágo ou duodeno, levantou-se a hipótese de se tratar de acalásia do. piloro. Por isso, foram solicitadas novas radiografias, tiradas em. séríe, tendo o paciente ingerido, na véspera, ứm copo e meio de contraste. Êste exame não afirmou, mas até certo ponto réforçoụ a hipótese de acalásia; e, realmente, não somente ainda desta vez não se encontrou lesão orgânica, como ainda mais, oito horas após a, ingestão do contraste, praticamente todo êle se encontrava no estômago (fig. 3). E' bem de vêr que, a rigor, não se podia af̣astar a hipótese de acalásia do piloro.

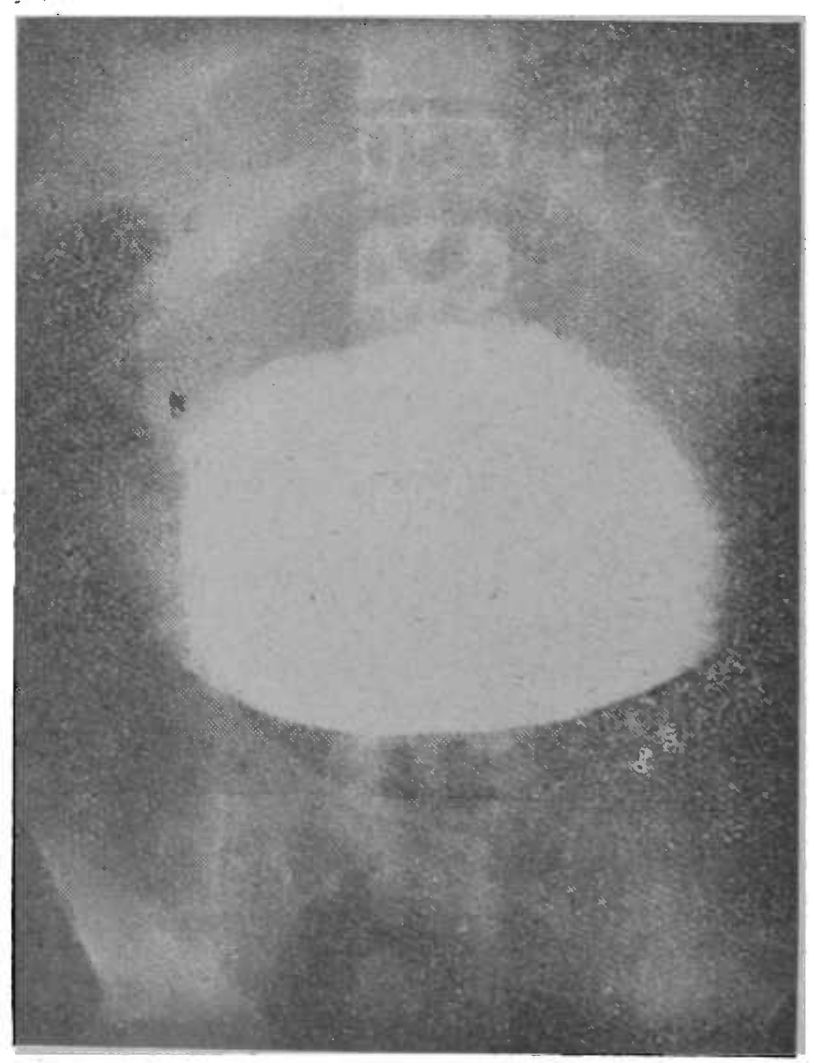

Fig. 3

Radiografia tirada oito horas após a ingestão de um copo e meio de contraste, mostrando que o mesmo ainda está quasi todo dentro do estômago. 
A hipótese de câncer duodenal deveria ser apenas remotamente lembrada, devido à extraordinária rarìdade dessa localização do câncer: recorde-se que os tumores do duodeno são tão raros quanto são frequentes os do estômago (1).

O diagnóstico do caso apresentava-se assim duvidoso: Câncer do estômago? Úlcera duodenal? Acalásia do piloro? Câncer duodenal?

De qualquer modo, era facil de se compreender que o tratamento cirúrgico se impunha. Após tratamento pre-operatório feito com particular esmero pois que a moléstia levara o paciente a um precário estado geral, em 27 de Fevereiro foi operado pelo Prof. Alipro Correita NeTO.

Anestesia peridural: $60 \mathrm{cc}$ de novocaina a $2 \%$ com X gotas de adrenalina. Punção entre D12-L $\mathrm{L}_{1}$ Boa.

Aberto o peritônio, é constatada a existência de uma grande cicatriz na face anterior do duodeno; o duodeno, a êsse nível, está endurecido e confunde-se com o piloro. Pensa-se em úlcera duodenal estenosante, e é praticada então, com pleno êxito, gastrectomia parcial a ReIchel-Polya.

$\mathrm{Na}$ peça operatória, consistente de $2 / 3$ de estômago e mais uma porção de duodeno numa extenșão de cêrca de $2,5 \mathrm{cms}$., notou-se a

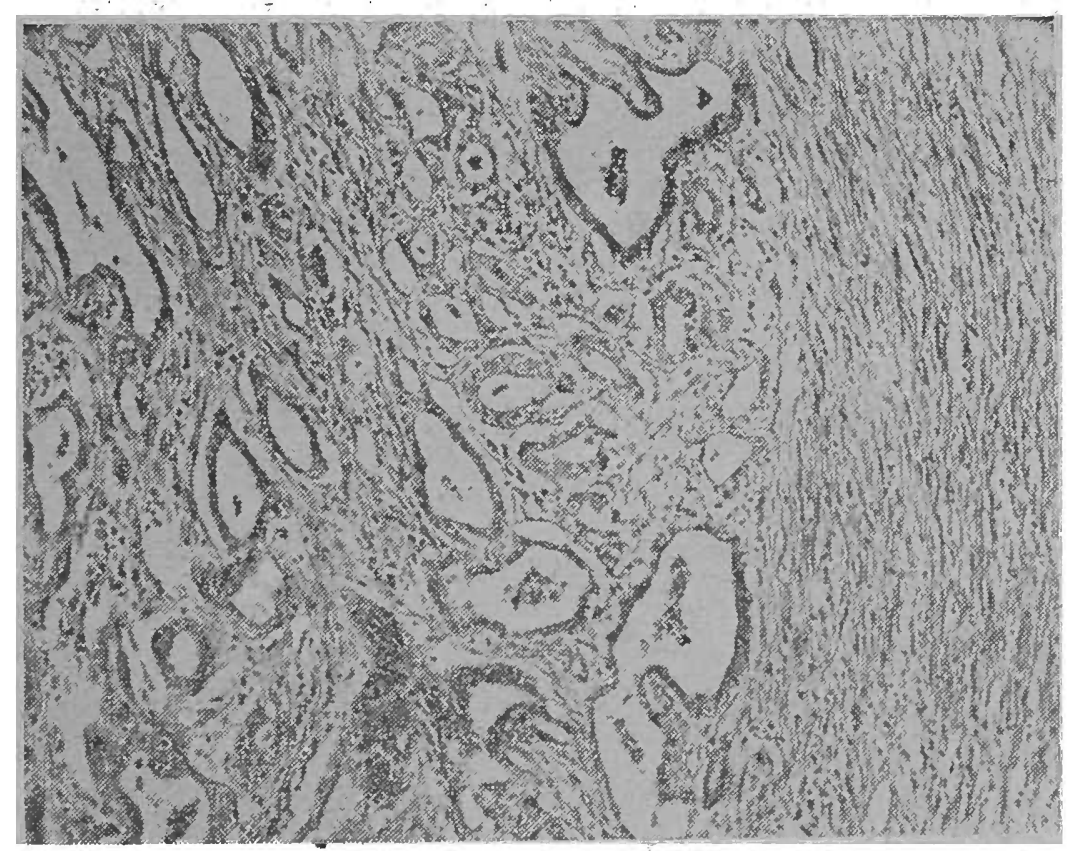

Fig. 4

Adenocarcinoma.

presença, no limite entre estômago e duodeno, de uma úlcera redonda, com diâmetro de $1 \mathrm{~cm}$., de bordos espessos, duros, infiltrados principalmente na parte contígua ao dưdẹno. Nessa porção, não

(1) Em trabalho que publicamos recentemente $\epsilon \mathrm{m}$ colaboração com E. J. ZERBINI (Rev. Cir. S. Paulo, 6(4),233-276-Jan.-Fev.1941), sobre a sticidereia dos tumbres do tracto gastrointestinal, encentramos, para 442 casos de tumores malignos do estômago, apenas dois no duadeno. - 
era possível a identificação macroșcópica segura do piloro, e consequentemente, não se estava habilitado a dar um pronunciamento definitivo sôbre o verdadeiro sítio da lesão: se no estômago ou se no duodeno. Acresciam ainda dificuldades decorrentes da retração dos tecidos vizinhos.

Ficava assim estabelecido, de modo' definitivo, que se tratava de uma lesão orgânica: a hipótese de acalásia do piloro não tinha mais razão de ser. Verificou-se histologicamente, tratar-se de um adeno-carcinoma ulcerado do pilớo (Dr. PAULo TIBIRIÇÁ) (fig. 4).

Localizava-se exatamente no limite entre estômago e duodeno, e a infiltração neoplástica era tão intensa que não era possível reconhecer o piloro, do qual apenas restaram, aqui e acolá; raras fibras musculares. No ponto onde estava 0 tumor, não era possível dizer, devido às alterações estruturais, se se tratava de estômago ou duodeno. Seguindo-se a massa tumoral, encontrava-se de um lado parede gástrica e de outro parede duodenal, tendo-se mesmo a impressão de que esta fora mais comprometida (fig. 5).

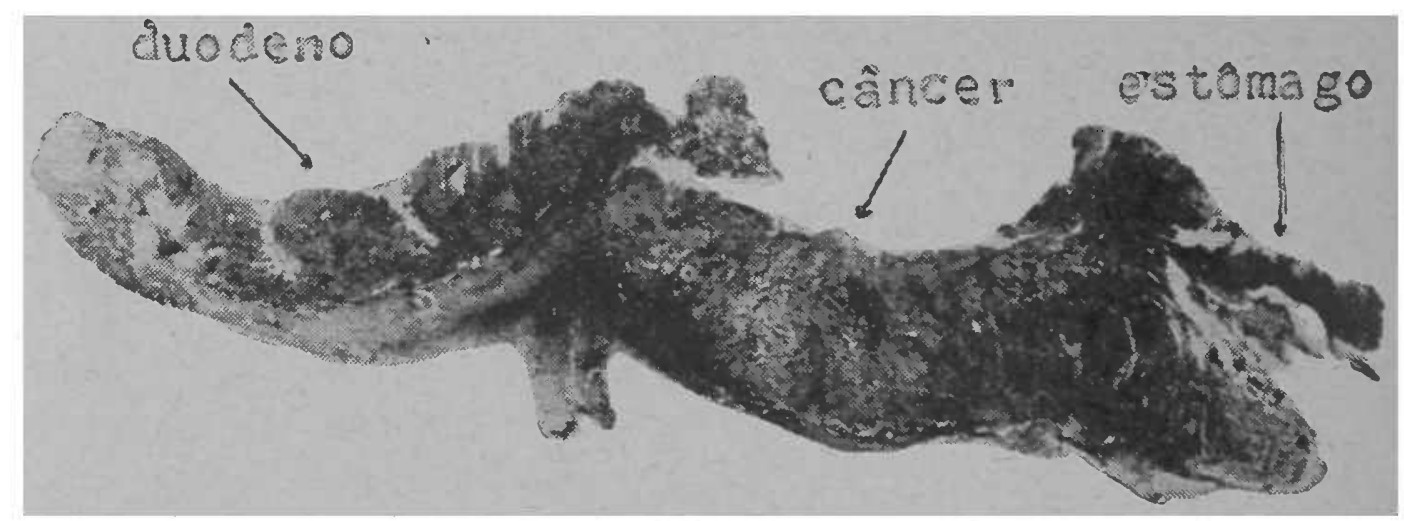

FIG. 5

Córte com ligeiro aumento, feito longitudinalmente, para mostrar a situação do tumor em, relação ao duodeno e estômago.

Ora, é sabido que o câncer gástrico respeita o piloro: êle rer presenta uma barreira onde o câncer do estômago para abrutamente. São raros os casos citados na literatura médica de câncer do estộmagọ tránspondo o piloro e invadindo o duodeno; e isto se dá em alguns poucos casos, em que o tumor é muito grande, havendo já estabelecido condições de inoperabilidade.

$E^{\prime}$ de particular interêsse, por conseguiñte, o presente caso, por isso que se tratava de um câncer' de pequenas dimensões e que se assestara exatamente sôbre o piloro, invadindo em pequena extensão e da cada lado o estômago e duodeno.

O paciente teve alta, curado, em 23 de Março.

Ingressou para o Serviço de follow-up; sete meses apỏs á operação, voltou á enfermaria. Passava bem, sentindo-se completamente 
são. Engordara oito quilos e entregava-se aos seus trabalhos costumeiros:

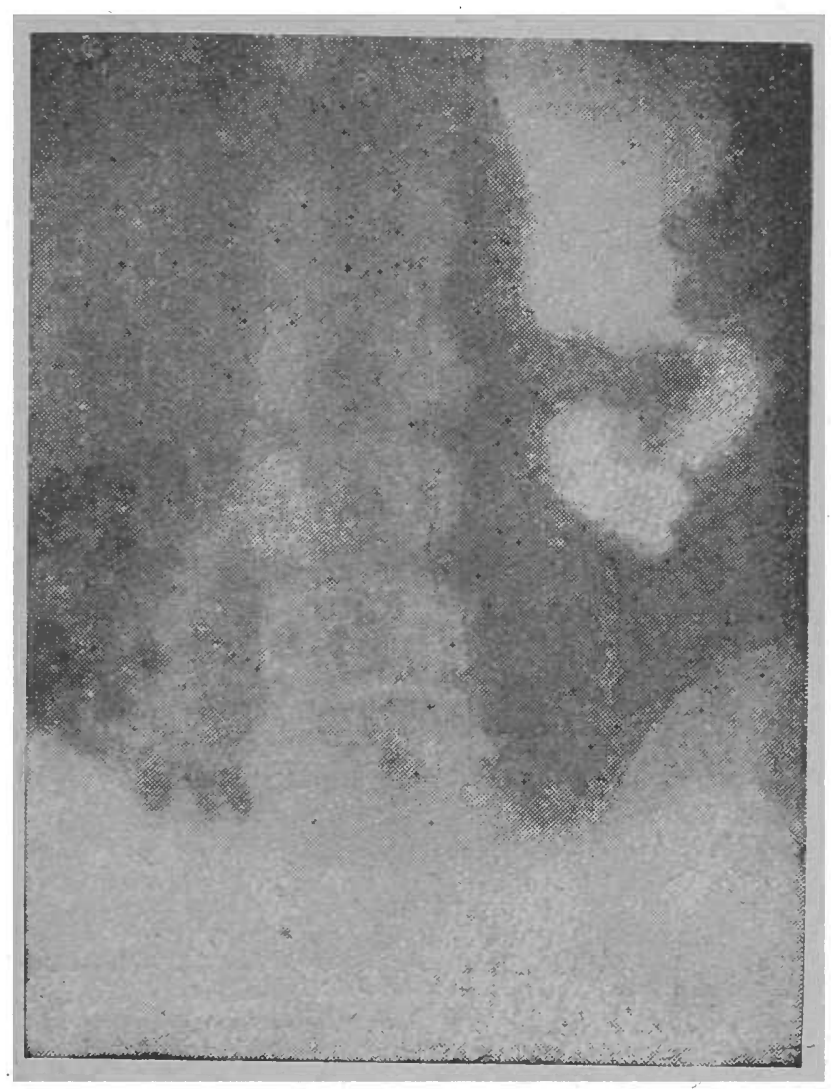

Fig. 6

Radiografia tirada sete meses após a operação, mostrando normalidade.

Foi solicitado exame radiológico (fig. 6) para documentar as condições atuais. "Gastrectomia parcial. Boa permeabilidade da bôca anastomótica. Aúsência de lesão ulcerosa no estômago restante e alça jejunal anästomosada." 
e estimulo à celula nervosa

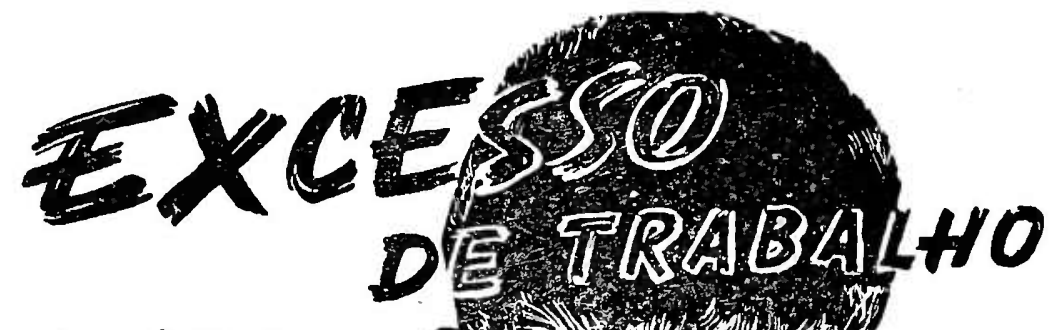

... exige alimento

Nergofon

encerrando $35 \mathrm{mg}$. de fós-

foro elementar por ampôla de 2 cmc., em combinação organocálcica, exerce essa dupla ação de maneira rápida e duradoura.

\section{AMOSTRAS}

à disposição dos

Srs. Médicos

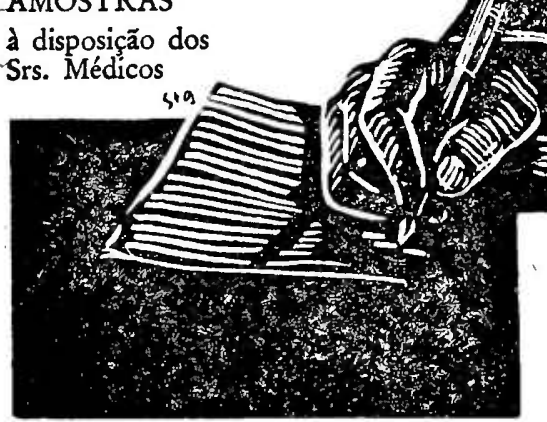

I NSTITUTO MEDICA MENTA ESTABELECIMENTO CIENTIFICO INDUSTRIAL FONTOURA \& SERPE - SÃO PAULO - BRASIL

붕
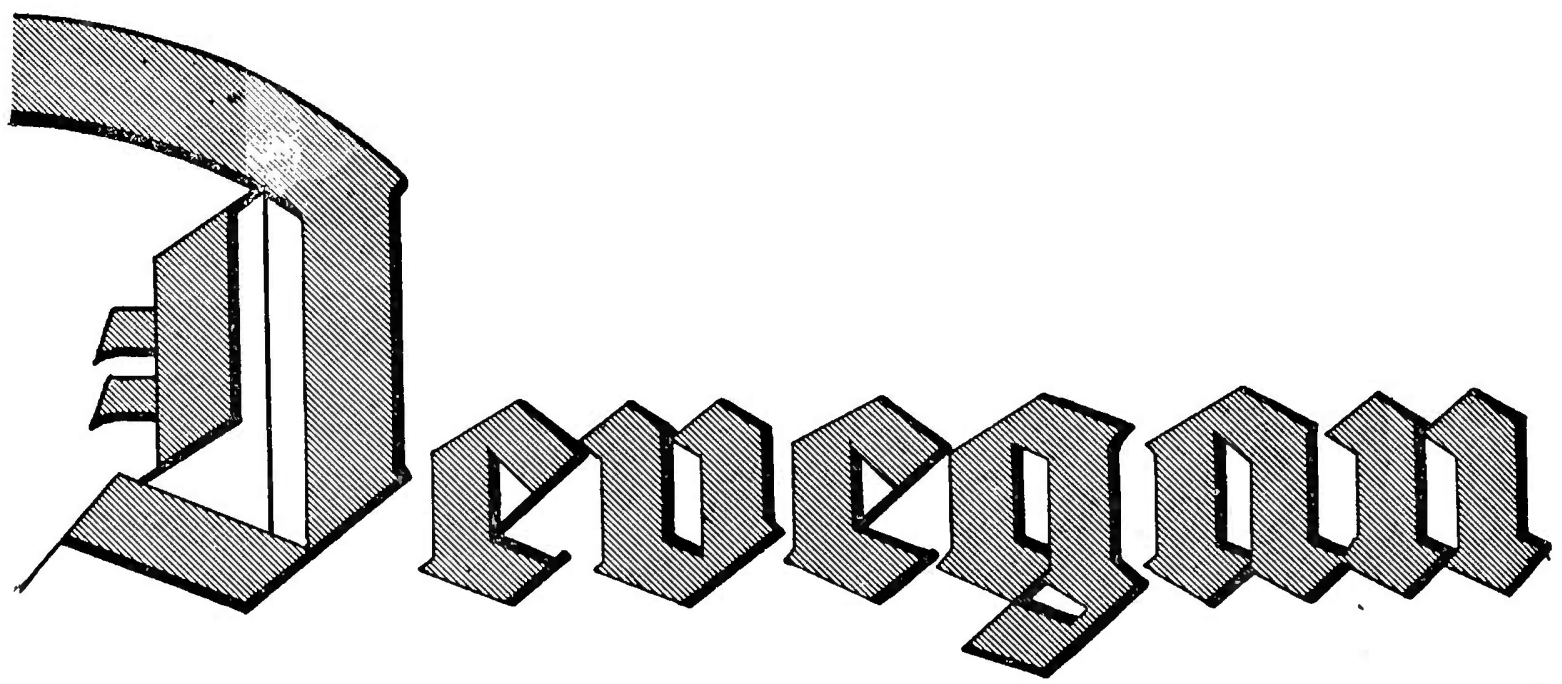

Para o tratamento dos fluxos vaginais de qualquer natureza, inclusive os frequentes e persistentes corrimentos produzidos pelos tricomonas. Permite um tratamento bio-etiologico pelo favoravel reforçamento da fauna microbiana naturál.

Embalagem original:

vidro de 30 comprimidos de $1 \mathrm{gr}$

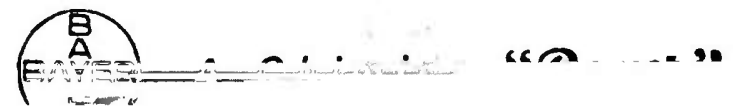

